\title{
Factors affecting engagement between academic faculty and decision-makers: learnings and priorities for a school of public health
}

Nasreen S. Jessani i D, Sameer M. Siddiqi, Carly Babcock, Melissa Davey-Rothwell, Shirley Ho and David R. Holtgrave

\begin{abstract}
Background: Schools of public health (SPHs) are increasingly being recognised as important contributors of human, social and intellectual capital relevant to health policy and decision-making. Few studies within the implementation science literature have systematically examined knowledge exchange experiences within this specific organisational context. The purpose of this study was therefore to elicit whether documented facilitators and barriers to engaging with government decision-makers resonates within an academic SPH context. We sought to understand the variations in such experiences at four different levels of government decision-making. Furthermore, we sought to elicit intervention priorities as identified by faculty.

Methods: Between May and December 2016, 211 (34\%) of 627 eligible full-time faculty across one SPH in the United States of America participated in a survey on engagement with decision-makers at the city, state, federal and global government levels. Surveys were administered face-to-face or via Skype. Descriptive data as well as tests of association and logistic regression analyses were conducted using STATA.

Results: Over three-quarters of respondents identified colleagues with ties to decision-makers, institutional affiliation and conducting policy-relevant research as the highest facilitators. Several identified time constraints, academic incentives and financial support as important contributors to engagement. Faculty characteristics, such as research areas of expertise, career track and faculty rank, were found to be statistically significantly associated with facilitators. The top three intervention priorities that emerged were (1) creating incentives for engagement, (2) providing funding for engagement and (3) inculcating an institutional culture around engagement.

Conclusions: The data suggest that five principal categories of factors - individual characteristics, institutional environment, relational dynamics, research focus and funder policies - affect the willingness and ability of academic faculty to engage with government decision-makers. This study suggests that SPHs could enhance the relevance of their role in health policy decision-making by (1) periodically measuring engagement with decision-makers; (2) enhancing individual capacity in knowledge translation and communication, taking faculty characteristics into account; (3) institutionalising a culture that supports policies and practices for engagement in decision-making processes; and (4) creating a strategy to expand and nurture trusted, relevant networks and relationships with decision-makers.
\end{abstract}

Keywords: Knowledge translation, Dissemination, Knowledge exchange, Evidence-informed decision-making, School of public health

\footnotetext{
* Correspondence: njessani@jhu.edu

Johns Hopkins Bloomberg School of Public Health, 624 North Broadway,

Baltimore, MD 21205, United States of America
}

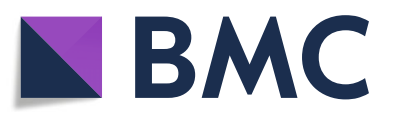

(c) The Author(s). 2018 Open Access This article is distributed under the terms of the Creative Commons Attribution 4.0 International License (http://creativecommons.org/licenses/by/4.0/), which permits unrestricted use, distribution, and

reproduction in any medium, provided you give appropriate credit to the original author(s) and the source, provide a link to the Creative Commons license, and indicate if changes were made. The Creative Commons Public Domain Dedication waiver (http://creativecommons.org/publicdomain/zero/1.0/) applies to the data made available in this article, unless otherwise stated. 


\section{Background}

\section{The use of research evidence in decision-making}

A major focus of dissemination and implementation research is to enhance evidence-informed decision-making (EIDM) by exploring "how, when, by whom, and under what circumstances evidence spreads" to a variety of public health decision-making settings, including government agencies and legislatures [1]. Promoting EIDM therefore helps strengthen public health systems and institutions, assists in the attainment of domestic public health goals and contributes to global development agendas [2]. Research evidence produced by academic institutions, amongst others, has the potential to play a critical role in policy formulation, implementation, quality improvement, and policy maintenance and evaluation [3-7]. Similarly, practice-based insights and implementation strategies have important implications on research agenda-setting, measurement approaches and evaluation opportunities $[8,9]$.

In recognition of the value of EIDM, researcher engagement in decision-making has been growing [10]. In this context, academic researcher engagement refers to outreach and exchange between researchers and decisionmakers in government on substantive issues related to researchers' technical expertise or affiliation. Researchers benefit from this engagement as practice-based insights have the potential to enhance the responsiveness, reach and utility of research produced [11, 12] through knowledge translation (KT). However, there are a variety of factors that facilitate or hinder this kind of engagement.

\section{Current evidence on facilitators and barriers to engagement between researchers and decision-makers}

Facilitators and barriers to KT in practice and policy sectors have been explored extensively within the implementation science literature from the perspectives of decision-makers $[7,13-16]$ as well as of researchers $[14,16]$. Results indicate that barriers can be attributed to individual characteristics $[17,18]$, institutional environments $[12,13,19,20]$, and trusting relationships between both parties [13, 17, 21-23]. Common individual-level facilitators for researchers include knowledge of the policy-making process and stakeholder groups, access to decision-makers, perceived credibility [24], and training or mentorship in communication strategies $[12,13]$. Common institutional-level facilitators include academic incentives for engagement, requirements or guidance from research funders, and alignment between research and legislative timelines $[13,25]$. Barriers to engagement include non-receptive policy environments, practical limitations to implementation of policy options (i.e. resource constraints) and conflicts related to politically sensitive findings $[13,26]$. Conversely, facilitators to engagement with decision-makers are often found to be related to research or evidence that was timely, relevant, had clear recommendations and was in line with the strategic goals of decision-makers [13, 21, 27].

However, a majority of the studies have focused on factors affecting research utilisation [7, 13, 20, 28-30] in contrast to knowledge exchange or engagement, as noted by Jacobson [20], who called for "more investigation of the factors that promote or impede engagement in knowledge transfer." Furthermore, as noted in Orton's systematic review [29], several stem from countries with universal healthcare systems such as United Kingdom, Canada and Australia. The context in the United States of America is notably quite different given the absence of such a health system and the influence of state-centred federalism on public health [31]. Furthermore, existing studies provide a comprehensive listing of individual (and at times institutional) facilitators and barriers to research utilisation but not the association between these and their combined effects on engagement.

The perspectives that underlie these studies deserve further comment. Current literature has evaluated policymaker [7, 13, 16, 25, 32, 33] and researcher perspectives $[12,15,17,34-39]$. However, the unique research environment of an academic researcher versus that of others warrants further attention, particularly those embedded within specialised graduate schools.

\section{The role of academia in EIDM}

There are several examples of academia contributing to health policy development and reform, and innovative examples of engagement between institutes of higher education and decision-makers have emerged globally. These include the participation of researchers from academic institutions in technical government working groups [40], researcher engagement in multi-stakeholder consortiums or coalitions [41], student policy fellowship programmes [42], and the hosting of forums by academic institutions for deliberative policy dialogues [43, 44], amongst others. Additionally, personal and professional relationships between academics and decision-makers have been shown to affect EIDM through a knowledge brokering role [45-47].

Academia is considered to be an environment where critical thinking and theory utilisation are valued, where independent and credible research is honored, and where policy and practice-relevant inquiry is encouraged [12]. However, research in the academic environment is often accompanied by faculty responsibilities to teaching and service [10]. These multiple responsibilities and incentives that accompany them may at times be incongruent with respect to engaging with decision-makers, as engagement with decision-makers is often under-valued in appointments and promotions guidelines relative to peer-reviewed publications, grants, teaching and other core tasks [20, 48, 49]. 
The extent to which knowledge sharing occurs is likely to vary across contexts given the many channels through which academic researchers engage with decision-makers. For instance, a study on medical faculty interactions with non-academics in Canada demonstrated the importance of faculty profiles when considering personal interactions [50]. In the field of public health, where EIDM has the potential to impact millions of lives, it is important to understand how academic settings could contribute to enhancing researcher engagement with decision-makers in government. Schools of public health (SPHs) are especially critical to advancing $\mathrm{KT}$ given their applied orientation and mandate. Given that they can have a significant impact in influencing EIDM $[23,51,52]$, factors affecting this potential need to be better understood [53].

\section{The context of SPHs in the United States of America}

SPHs have played a foundational role in the emergence, differentiation and legacy of public health over the past century [3, 54]. In particular, SPHs have facilitated education and research in several areas of public health, including contagion, preventive health, health system design and delivery, primary healthcare and health promotion [55]. It is for these reasons, and the significant potential of public health, that Colgrove et al. characterise SPHs as "essential infrastructure of a responsible society" [31].

The importance of enhanced linkages between SPHs and government public health agencies in the United States was emphasised first in the 1980s by the Institute of Medicine Future of Public Health Report, which concluded that "schools of public health have in recent years become somewhat isolated from the field of public health practice" [56]. WHO also highlighted the necessary role of SPHs in transforming medical care systems [57]. SPHs responded with some results published in The Public Health Faculty/Agency Forum report [58] and the Pew Commission report [59].

Attention to the role of SPHs has not gone unnoticed as reflected in studies dedicated to studying their influence on decision-making [51, 60-63]. However, there is relatively limited understanding of the factors that influence engagement between SPH academic researchers and government decision-makers, how the individual and institutional factors interact, and how this may be different at the city, state, federal and global levels. This is critical for informing and building new interventions that can increase the bidirectional interchange between SPH faculty and decision-makers.

\section{Objectives and justification for this study}

Utilising the extant research literature available, we sought to fill the abovementioned gaps so as to contribute to the discussion on interventions for supporting engagement of SPH faculty with decision-makers for purposes of knowledge exchange. Furthermore, we sought to explore relationships with decision-makers at four different government levels to reflect the local as well as global reach of the SPH in the study.

The purpose of this study was therefore threefold, namely, within the context of an SPH, to (1) explore the extent to which perceptions of individual, institutional, relational, research-related and funder-related factors affect academic faculty engagement with public health decision-makers, (2) involve faculty in identifying priorities to enhance engagement, and (3) utilise this insight to suggest recommendations for enhancement of facilitators and mitigation of barriers to engagement within the SPH.

\section{Methods}

\section{Eligibility and recruitment}

The Johns Hopkins Bloomberg School of Public Health (JHSPH) is located in Baltimore, MD, approximately 40 miles from Washington, DC. As the first and largest SPH globally, it hosts approximately 2340 students and 1500 faculty spanning 10 departments and 60 centres/institutes [64]. Between June and November 2016, all full-time faculty at JHSPH were invited to participate in the study. Engagement with decision-makers was not a requirement for participation nor was conducting research. After initial invitations were sent, those whose status was not verifiable, or were no longer employed by the institution, were reclassified as ineligible. This approach was taken to focus on existing full-time faculty members' engagement behaviours. Three attempts at recruitment were made over the 6-month period, with invitations being sent out via email for the first two attempts and phone calls made for the final recruitment attempt. For those without valid or accessible phone numbers, a final attempt was made via email. Consent forms (for verbal consent if accepted) and a 'frequently asked questions' flyer on study goals and objectives was shared during follow-up invitations.

\section{Data collection}

Data were collected through an interviewer-administered survey, which was conducted either via video Skype or in-person. The survey tool was adapted from a prior study [46] and refined by the study team. It was tested with faculty ineligible for the study but with similar characteristics to the target respondents. Survey responses were entered into Qualtrics Software [65]. All interviewers were members of the study team and performed simulations to ensure alignment in the approach and intent of the surveys. The survey took approximately $60 \mathrm{~min}$, on average, to complete.

The survey consisted of three sections, as follows: (1) questions regarding respondents' demographic and institutional affiliation, (2) perception of factors affecting 
their engagement with decision-makers, and (3) their suggested priorities for the $\mathrm{SPH}$ in enhancing researcher engagement with decision-makers. 'Engagement' was defined as interaction, communication, outreach or exchange that was active or underway during the period of study.

Respondents were also asked to provide the names of up to seven decision-makers at the Baltimore city, Maryland state, United States federal, and global levels with whom they are currently engaged (i.e. have some form of interaction or communication on a relevant issue in the 12 months preceding and up to the time of the study). Given that decision-making happens at various levels that may or may not be policy relevant, we focused the study on relationships with 'decision-makers'. For the purposes of this study, a decision-maker was defined as someone who plays a key role in the administration (and leadership) of a government organisation that has the authority to influence or achieve specific health goals (e.g. administrative actions, guidelines and recommendations and policy decisions). These data were used to conduct a network analysis (reported elsewhere) [66] and generate the number of decision-makers each respondent was engaged with.

The list of facilitators and barriers was compiled from studies and reviews in the knowledge exchange and brokering literature that focused on academic researchers, advocates and decision-makers' engagement experiences $[13,18,23,33,67-69]$ as well as from responses received during instrument testing. In developing the survey, we noted that factors (facilitators as well as barriers) documented in the literature could be categorised within five loci of perceived control, namely individual characteristics, institutional environment, relational dynamics, research focus and funder policies, when considering knowledge exchange endeavours in contrast to knowledge utilisation. These categories were neither shared in advance with respondents nor were they presented in this order so as to minimise response bias. For each of the final list of 19 factors, respondents were requested to indicate, based on their personal experiences, whether it had been a facilitator, a barrier (i.e. whether its presence or absence was a hindrance), both a facilitator and a barrier, or neither.

The list of 11 priorities they could select from were based on recommendations included in prior studies of facilitators and barriers to engagement in academic settings, as well as proposed strategies at JHSPH $[12,13]$. Respondents were asked to identify the top three priorities that the school should pursue at an institutional-level to promote faculty engagement with decision-makers; respondents were invited to suggest priorities that had not been listed.

\section{Data analysis}

Respondents were anonymised and assigned a unique identification number prior to analysis. Some response variables related to faculty characteristics (e.g. areas of research expertise) were grouped into broader categories to assist with analysis. Categorical data with low response counts were collapsed for conceptual and analytic purposes (i.e. faculty position, number of years employed within the institution, race/ethnicity and department categories). Data were analysed using STATA $13.1[70]$.

In order to understand whether influential factors varied by demographic attributes, research foci, network size (total number of government decision-makers they are connected to at the city, state, federal and global levels) or engagement experience, multiple $x^{2}$ tests or, where appropriate, Fisher's exact test and univariate logistic regressions were performed. The characteristics included in analyses were faculty track and position, research area of expertise, the number of years employed within the institution and departmental affiliation. The relative risk of whether factor rating (i.e. the outcome variable) varied by network size was explored using logistic regression. To explore this association, a dichotomous variable was created for each factor affecting engagement; responses were coded as ' 1 ' if they were identified as a facilitator and ' 0 ' if they were identified as a barrier.

\section{Results \\ Respondent characteristics}

A total of 627 full-time faculty were eligible for inclusion in the study; this group consisted of tenure and non-tenure track faculty, as well as faculty in professorial and scientist career tracks. Within the context of this study, faculty in the professorial track have responsibilities primarily related to teaching and advising students, research and academic programme management, and include individuals with the titles Associate Professor, Assistant Professor and Professor. Faculty in the scientist track have responsibilities primarily related to research and project management and include individuals with the titles Research Associates, Associate Scientist, Assistant Scientist and Senior Scientist.

Of those, 211 (34\%) participated in the study. Table 1 provides an overview of study respondents. Professors were the largest group amongst respondents (23\%), followed by Associate Professors (12\%), Assistant Professors (13\%), Assistant Scientists (17\%) and Research Associates (13\%). Approximately $22 \%$ of respondents indicated holding joint appointments in two or more departments. With regard to career track, approximately $50 \%$ of respondents reported being in a professorial track and $46 \%$ in a scientist track. The distribution of faculty within the study sample was similar to the school-wide distribution reported in 2016 in terms of sex, race/ethnicity, position and career [71]. 
Table 1 Respondent characteristics

\begin{tabular}{|c|c|c|c|}
\hline & Total Respondents (N) & Total Respondents (\%) & Total Faculty in the SPH (\%) \\
\hline Respondents & 211 & 34 & \\
\hline \multicolumn{4}{|l|}{ Sex } \\
\hline Male & 88 & 42 & 43 \\
\hline Female & 123 & 58 & 57 \\
\hline \multicolumn{4}{|l|}{ Race/Ethnicity } \\
\hline White & 169 & 80 & 74 \\
\hline Black or African-American & 7 & 3 & 5 \\
\hline Hispanic or Latino & 4 & 2 & 4 \\
\hline Asian & 20 & 9 & 16 \\
\hline Other & 9 & 4 & - \\
\hline \multicolumn{4}{|l|}{ Faculty position } \\
\hline Professor & 49 & 23 & 25 \\
\hline Associate Professor & 25 & 12 & 12 \\
\hline Assistant Professor & 28 & 13 & 13 \\
\hline Senior Scientist & 9 & 4 & - \\
\hline Associate Scientist & 19 & 9 & - \\
\hline Assistant Scientist & 35 & 17 & - \\
\hline Senior Research Associate & 6 & 3 & - \\
\hline Research Associate & 28 & 13 & - \\
\hline Other & 12 & 6 & - \\
\hline \multicolumn{4}{|l|}{ Faculty track } \\
\hline Professorial & 105 & 50 & 49 \\
\hline Scientist & 97 & 46 & 48 \\
\hline \multicolumn{4}{|c|}{ Number of years at the institution } \\
\hline Less than 3 years & 50 & 24 & - \\
\hline 3 to 5 years & 40 & 19 & - \\
\hline 6 to 10 years & 45 & 21 & - \\
\hline 11 to 20 years & 33 & 16 & - \\
\hline Greater than 20 years & 43 & 20 & - \\
\hline \multicolumn{4}{|c|}{ Leadership position within the institution } \\
\hline Yes & 81 & 39 & - \\
\hline No & 128 & 61 & - \\
\hline \multicolumn{4}{|c|}{ Current engagement with decision-makers in government } \\
\hline Not currently engaged & 57 & 27 & - \\
\hline Currently engaged & 154 & 73 & - \\
\hline Baltimore City & 44 & $21^{a}$ & - \\
\hline Maryland State & 50 & $24^{\mathrm{a}}$ & - \\
\hline United States Federal & 95 & $45^{\mathrm{a}}$ & - \\
\hline Global & 77 & $37^{\mathrm{a}}$ & - \\
\hline Other cities, states, counties & 21 & $10^{a}$ & - \\
\hline
\end{tabular}

${ }^{a}$ Indicates percentage of the total number of respondents $(n=211)$

Respondents identified over 23 areas of research expertise; these subject areas were collapsed into 13 distinct categories. Several respondents identified more than one focus; the number of areas of research expertise per respondent ranged from 1 to 13. The top listed areas of expertise included infectious disease, 
epidemiology and disease control, maternal and child health, health behaviour, and non-communicable diseases.

Approximately $51 \%$ of respondents indicating having engaged with decision-makers prior to joining as faculty. Engagement levels increased at all levels of government after joining the university, with $83 \%$ of respondents reporting engaging with decision-makers since joining as faculty and $73 \%$ reporting being currently engaged.

\section{Perceptions of facilitators and barriers to engagement}

Percent frequency data for respondent's perceptions of facilitators and barriers to engagement with decisionmakers are presented in Table 2 . The complete phrasing of each factor included in the survey is provided in the column labelled, 'Survey Phrasing'. A two-word contraction for each factor is provided in the column labelled, 'Factor' which is used henceforth.

The primary facilitators identified by respondents ranged in responses from approximately 66\% (Personal Networks; KT Skills) to 78\% (Peer Introductions; Institutional Affiliation; Research Relevance). The range of responses for the top five barriers was much lower and much wider, from approximately 15\% (Departmental Reimbursement; Workplace Location; Academic Incentives; Career Stage) to 43\% (Dedicated Time).

\section{Individual characteristics}

Experiential Knowledge was acknowledged by $65 \%$ of faculty as a contributing factor to engagement. Respondents in more junior faculty appointments, specifically Research Associates, Assistant Scientists and Assistant Professors reported Career Stage and Faculty Position as a facilitator $20 \%$ and $18 \%$, respectively, less frequently than the sample mean. Although $86 \%$ of respondents noted the importance of KT Skills, responses were similar across academic positions (i.e. there was no statistically significant association between academic position and whether this factor was identified as a facilitator or barrier, $p=0.701$ ).

\section{Institutional factors}

Approximately $64 \%$ of respondents did not consider the availability or absence of Departmental Reimbursement to affect their engagement with decision-makers in government. There was, however, some variation in the role of this factor in by academic position, wherein Assistant Professors reported reimbursement from the department as a facilitator $20.1 \%$ more frequently than the sample mean.

Although the majority of faculty (52\%) concurred that Academic Incentives affect engagement with decisionmakers, $41 \%$ of respondents indicated that it was irrelevant. However, how academic incentives were rated varied by academic position. For instance, Assistant Professors reported the lack of academic incentives for engagement as a barrier $27.9 \%$ more frequently than the overall sample mean.

With Baltimore being approximately 40 miles from Washington DC, it is not surprising that approximately half $(46.9 \%)$ of all respondents identified Workplace Location as a facilitator. Faculty in departments with research foci at the international level reported their location as a facilitator approximately $18.1 \%$ less frequently than the sample mean.

Respondents in departments whose work directly informed policy development and evaluation were found to report Departmental Culture as a facilitator approximately $16 \%$ more frequently than the sample mean, whereas respondents in departments that traditionally were not focused on policy reported it as a facilitator between $19 \%$ and $25 \%$ less frequently than the sample mean. Nevertheless, the extent to which Departmental Culture was considered a facilitator varied by department, and the association between whether it was reported a facilitator and respondents' departmental affiliation was found to be significant $(p=0.027)$ (Table 3$)$. There were also differences in terms of academic position, wherein Associate Professors reported Departmental Culture as a facilitator $20 \%$ less frequently than the sample mean. All Department Chairs who responded to the survey noted that it was an important facilitator. KT Skills and Peer Skills also varied between departments, with at least two departments reporting these as a facilitator $21 \%$ more frequently than the sample mean.

The most commonly cited barrier, identified by $43 \%$ of respondents, was the availability of Dedicated Time for engagement. Informally, however, several respondents noted that it parallels how they feel about academic incentives, in that time is an important academic incentive and is therefore nested within other factors. Conversely, Institutional Affiliation was one of the three highest cited facilitators $(78 \%)$ and did not have a statistically significant association with department $(p=0.749)$.

\section{Relational dynamics}

There were several factors that fell under the category of Relational Dynamics. Amongst these, each was noted as a facilitator as follows: Personal Networks (66\%), Peer Introductions (78\%), Network Culture (60\%) and Peer Skills (62\%). However, between $15 \%$ and $30 \%$ did not consider these as relevant factors at all. The extent to which respondents identified Personal Networks and Peer Introductions as facilitators varied by department.

\section{Funder policies}

Less than half of respondents (43.1\%) identified External Funding as a facilitator for engagement. Funder 
Table 2 Distribution of responses for perceptions of facilitators and barriers to engagement

\begin{tabular}{|c|c|c|c|c|c|}
\hline Factor & Survey phrasing & $\begin{array}{l}\text { Facilitator } \\
\mathrm{n}(\%)\end{array}$ & $\begin{array}{l}\text { Barrier } \\
\text { n (\%) }\end{array}$ & $\begin{array}{l}\text { Both } \\
\mathrm{n}(\%)\end{array}$ & $\begin{array}{l}\text { Neither } \\
\mathrm{n}(\%)\end{array}$ \\
\hline \multicolumn{6}{|l|}{ Individual characteristics } \\
\hline Experiential knowledge & $\begin{array}{l}\text { "Previous professional/practical experience in a } \\
\text { decision-making environment" }\end{array}$ & $115(55)$ & $20(10)$ & $6(3)$ & $70(33)$ \\
\hline Career stage & "Stage I am at in my professional career" & $104(49)$ & $47(22)$ & $22(10)$ & $38(18)$ \\
\hline Faculty position & $\begin{array}{l}\text { "My (academic or administrative) role/position } \\
\text { at JHSPH" }\end{array}$ & $114(54)$ & $27(13)$ & $23(11)$ & $47(22)$ \\
\hline KT skills & $\begin{array}{l}\text { "Communication/knowledge translation/ } \\
\text { advocacy skills" }\end{array}$ & $135(64)$ & $27(13)$ & $19(9)$ & $30(14)$ \\
\hline \multicolumn{6}{|l|}{ Institutional environment } \\
\hline Departmental reimbursement & $\begin{array}{l}\text { "Reimbursement by my department of costs } \\
\text { incurred as a result of engagement" }\end{array}$ & $41(19)$ & $33(16)$ & $2(1)$ & $135(64)$ \\
\hline Academic incentives & $\begin{array}{l}\text { "Academic incentives (e.g. contribution to } \\
\text { promotion and tenure) for engaging with } \\
\text { decision-makers on research results/ } \\
\text { priorities etc." }\end{array}$ & $73(35)$ & $39(19)$ & $13(6)$ & $86(41)$ \\
\hline Workplace location & "Geographic location of my workplace" & $99(47)$ & $31(15)$ & $18(9)$ & $63(30)$ \\
\hline Departmental culture & $\begin{array}{l}\text { "Culture of pursuing policy- and/or practice- } \\
\text { relevant research in my department" }\end{array}$ & $116(55)$ & $29(14)$ & $11(5)$ & $55(26)$ \\
\hline Non-financial support & $\begin{array}{l}\text { "Support (non-financial) from my } \\
\text { supervisor/department" }\end{array}$ & $122(58)$ & $27(13)$ & $13(6)$ & $49(23)$ \\
\hline Dedicated time & $\begin{array}{l}\text { "Ability to carve out dedicated time for } \\
\text { engagement with decision-makers" }\end{array}$ & $65(31)$ & $90(43)$ & $20(10)$ & $36(17)$ \\
\hline Institutional affiliation & $\begin{array}{l}\text { "Being affiliated with JHSPH (e.g. implied } \\
\text { credibility)" }\end{array}$ & $164(78)$ & $2(1)$ & $27(13)$ & $18(9)$ \\
\hline \multicolumn{6}{|l|}{ Relational dynamics } \\
\hline Personal networks & "My own pre-existing relationships/networks" & $139(66)$ & $17(8)$ & $10(5)$ & $45(21)$ \\
\hline Peer introductions & $\begin{array}{l}\text { "Introduction to decision-makers by colleagues } \\
\text { who have relevant relationships/networks" }\end{array}$ & $164(78)$ & $7(3)$ & $8(4)$ & $32(15)$ \\
\hline Network culture & $\begin{array}{l}\text { "Culture of policy engagement amongst my } \\
\text { professional network outside the SPH" }\end{array}$ & $126(60)$ & $12(6)$ & $9(4)$ & $64(30)$ \\
\hline Peer skills & $\begin{array}{l}\text { "Support from colleagues with communication/ } \\
\text { knowledge translation/advocacy skills" }\end{array}$ & $130(62)$ & $12(6)$ & $8(4)$ & $61(29)$ \\
\hline \multicolumn{6}{|l|}{ Research focus } \\
\hline Research relevance & $\begin{array}{l}\text { "Relevance of my research to pertinent } \\
\text { policy issues" }\end{array}$ & $164(78)$ & $5(2)$ & $23(11)$ & $19(9)$ \\
\hline Research implications & $\begin{array}{l}\text { "Inclusion of contextual, economic or } \\
\text { implementation-related implications of } \\
\text { my research" }\end{array}$ & $130(62)$ & 7 (3) & $14(7)$ & $60(28)$ \\
\hline \multicolumn{6}{|l|}{ Funder policies } \\
\hline External funding & $\begin{array}{l}\text { "Financial support/compensation from } \\
\text { external sources (funders) for engagement" }\end{array}$ & $91(43)$ & $24(11)$ & $38(18)$ & $58(28)$ \\
\hline Funder requirements & $\begin{array}{l}\text { "Requirements from funders regarding } \\
\text { dissemination and policy engagement } \\
\text { (e.g. lobbying restrictions, dissemination } \\
\text { beyond publications, etc.)" }\end{array}$ & $73(35)$ & $14(7)$ & $23(11)$ & $101(48)$ \\
\hline
\end{tabular}


Table 3 Association between faculty characteristics and factor rating using Fischer's exact test

\begin{tabular}{|c|c|c|}
\hline & Factor & $P$ value \\
\hline \multicolumn{3}{|l|}{ Faculty characteristic (n) } \\
\hline \multirow[t]{4}{*}{ Faculty track (211) } & Career stage & $<0.001$ \\
\hline & Departmental reimbursement & $<0.001$ \\
\hline & Faculty position & $<0.001$ \\
\hline & Personal networks & 0.020 \\
\hline \multirow[t]{2}{*}{ Years at Johns Hopkins University (211) } & Career stage & $<0.001$ \\
\hline & Experiential knowledge & 0.010 \\
\hline \multirow[t]{3}{*}{ Primary department ${ }^{\mathrm{a}}(143)$} & Peer introductions & 0.022 \\
\hline & Departmental culture & 0.027 \\
\hline & Funder requirements & 0.033 \\
\hline \multirow[t]{5}{*}{ Academic position ${ }^{\mathrm{a}}$ (145) } & Academic incentives & 0.009 \\
\hline & Institutional affiliation & 0.005 \\
\hline & Career stage & $<0.001$ \\
\hline & Departmental reimbursement & 0.003 \\
\hline & Faculty position & $<0.001$ \\
\hline \multicolumn{3}{|l|}{ Areas of expertise ${ }^{a}$} \\
\hline \multirow[t]{2}{*}{ Infectious disease (81) } & Peer skills & 0.004 \\
\hline & Funder requirements & 0.023 \\
\hline Non-communicable disease (43) & Knowledge translation skills & 0.044 \\
\hline \multirow[t]{3}{*}{ Maternal and child health (72) } & Peer introductions & 0.031 \\
\hline & Departmental culture & 0.016 \\
\hline & Personal networks & 0.005 \\
\hline \multirow[t]{3}{*}{ Health services and systems research (63) } & Research implications & 0.002 \\
\hline & Knowledge translation skills & 0.033 \\
\hline & Experiential knowledge & 0.001 \\
\hline Environmental and occupational health (47) & Knowledge translation skills & 0.017 \\
\hline \multirow[t]{3}{*}{ Nutrition (25) } & Peer skills & 0.018 \\
\hline & External funding & 0.009 \\
\hline & Knowledge translation skills & 0.013 \\
\hline \multirow[t]{6}{*}{ Health policy (63) } & Workplace location & 0.039 \\
\hline & Peer introductions & 0.046 \\
\hline & Research implications & 0.007 \\
\hline & Knowledge translation skills & $<0.001$ \\
\hline & Personal networks & 0.001 \\
\hline & Experiential knowledge & $<0.001$ \\
\hline \multirow[t]{3}{*}{ Health behaviour and promotion (64) } & Academic incentives & 0.041 \\
\hline & Departmental culture & 0.027 \\
\hline & Knowledge translation skills & 0.044 \\
\hline \multirow[t]{2}{*}{ Biomedical sciences (38) } & Departmental culture & 0.007 \\
\hline & Funder requirements & 0.030 \\
\hline
\end{tabular}

This table only includes statistically significant findings with $p<0.050$.

${ }^{a}$ For analytic purposes, only departments, academic positions and areas of expertise that accounted for greater than $10 \%$ of the sample were included in this analysis 
Requirements could have been considered a facilitator in the event that funders include engagement as a condition of funding, require dissemination of results and/or provide resources for engagement. It could have also been perceived as a barrier in instances where funders specifically prohibit engagement or do not provide resources to offset the costs of dissemination. Funder Requirements was found to have a statistically significant association with respondents' departmental affiliation $(p=0.033)$.

\section{Faculty characteristics predictive of perceptions of facilitators and barriers to engagement}

Research area of expertise, faculty track, faculty rank, engagement with decision-makers and number of relationships with decision-makers were faculty characteristics that were significantly associated with factors identified as facilitators.

\section{Faculty position and track}

The relevance of a factor also varied by faculty track. For example, there were statistically significant differences in whether Career Stage, Faculty Position and Personal Networks were identified as facilitators or barriers between faculty in scientist and professorial tracks (Table 3).

\section{Research areas of expertise}

The relevance of a factor often varied by respondents' areas of research expertise as seen in Table 3. For example, there were statistically significant $(p<0.05)$ differences in whether Personal Networks were identified as a facilitator or barrier between respondents that selected health policy and maternal and child health as their research areas of expertise.

\section{Engagement with decision-makers}

For most factors, there were statistically significant $(p<0.05)$ differences between faculty that were currently engaged with decision-makers relative to those that were not (i.e. Career Stage, Institutional Affiliation, Peer Introductions, Peer Skills, External Funding, Workplace Location, Funder Requirements, Faculty Position, KT Skills, Personal Networks, Network Culture, Experience Knowledge, Research Relevance, and Research Implications).

\section{Decision-maker network size}

As a faculty member's network size increased, they were more likely to identify the following factors as facilitators rather than barriers: Career Stage, Institutional Affiliation, KT Skills, Personal Networks, Network Culture and Experiential Knowledge (Table 4).
Table 4 Relative risk of factor rating by number of alters identified

\begin{tabular}{lll}
\hline Factor & Relative risk & $95 \%$ Confidence interval \\
\hline Career stage & 1.06 & $1.01-1.11$ \\
Institutional affiliation & 1.19 & $1.09-1.28$ \\
Knowledge translation skills & 1.07 & $1.01-1.12$ \\
Personal networks & 1.09 & $1.03-1.14$ \\
Network culture & 1.07 & $1.02-1.12$ \\
Experiential knowledge & 1.14 & $1.06-1.21$ \\
\hline
\end{tabular}

This table only includes statistically-significant findings with a $95 \% \mathrm{Cl}$ that does not include 1

\section{Priorities}

A complete list of priorities to enhance engagement with decision-makers, their contracted code and their percent frequency is provided in Table 5 . While priorities varied slightly across departments, the top three priorities for the SPH as indicated by respondents were More Incentives, Supplemental Funding and Enhancing Culture.

While the priorities varied across the departments in terms of where they ranked, there were many similarities. For instance, More Incentives ranked in the top three for all ten departments and ranked first for half of all departments. Supplemental Funding scored in the top three for seven of out of ten departments. Of note, Mentoring Support and Leverage Technology consistently scored in the bottom three across departments. While Strengthening KT Skills was noted by $32 \%$ of all faculty, $80 \%$ of department Chairs reported it as a priority. Similarly, Enhancing Culture was listed by $39 \%$ of faculty overall and $80 \%$ of department Chairs. Although responses differed by various respondent characteristics, logistic regression tests found that primary departmental affiliation, academic position, years within the institution and number of alters were generally not predictive of priority selection.

\section{Discussion}

This study demonstrates that individual characteristics, institutional factors, relational dynamics, research foci, as well as funder policies affect academic researchers' engagement with public health decision-makers. Moreover, these data suggest that factors differ in their status as a facilitator or barrier (in terms of respondents' institutional position, rank and department), as well as individual experiences (areas of research expertise, engagement with decision-makers and network size) similar to some of the findings from Ouimet et al. [50].

The most commonly cited facilitators identified in this study spanned relational, individual, institutional and research-related characteristics, whereas the most commonly cited barriers focused on institutional and 
Table 5 Percent frequency of institutional priorities to enhance engagements with decision-makers

\begin{tabular}{lll}
\hline Priority & Code & $\mathrm{n}(\%)$ \\
\hline $\begin{array}{l}\text { Create more academic incentives for such engagement } \\
\text { (e.g. contribution to promotion and tenure) }\end{array}$ & More incentives \\
$\begin{array}{l}\text { Provide supplemental funding for knowledge translation } \\
\text { and/or facilitate financial support/compensation from } \\
\text { external sources }\end{array}$ & Supplemental funding \\
$\begin{array}{l}\text { Enhance/inculcate a culture of pursuing policy- and/or } \\
\text { practice-relevant research }\end{array}$ & Enhancing culture \\
$\begin{array}{l}\text { Strengthen faculty (and student) capacity in communication/ } \\
\text { knowledge translation/advocacy skills }\end{array}$ & Strengthening knowledge translation skills \\
$\begin{array}{l}\text { Assist faculty with building and maintaining important } \\
\text { relationships/networks }\end{array}$ & Networking assistance \\
$\begin{array}{l}\text { Mediate/broker introductions to decision-makers by colleagues } \\
\text { who have relevant relationships }\end{array}$ & Mediating relationships \\
$\begin{array}{l}\text { Facilitate faculty in carving out dedicated time for } \\
\text { such engagements }\end{array}$ & Allocating time \\
$\begin{array}{l}\text { Promote and support experience in a decision-making } \\
\text { environment }\end{array}$ & Value experience \\
$\begin{array}{l}\text { Hire more faculty and staff with training in communication/ } \\
\text { knowledge translation/advocacy skills } \\
\text { Leverage technology to engage remotely with decision-makers } \\
\begin{array}{l}\text { Provide more mentoring/moral support from supervisors } \\
\hline\end{array}\end{array} \quad$ Hire knowledge translation faculty \\
\hline 63 (29.9)
\end{tabular}

individual factors. These findings are consistent with Oliver et al.'s [13] review of facilitators and barriers to knowledge exchange. The circumstances of academic researchers in a university setting are different to those of the researchers within other contexts. We have therefore sought to see if the barriers and facilitators resonate within this group and whether we can reinforce existing studies, and if not, to provide an alternate perspective. This study differs in that, instead of viewing individual as well as institutional determinants as separate, we explore them in conjunction to see if and how individual characteristics are associated with responses to institutional factors.

\section{Institutional characteristics}

Faculty responses to the various factors affecting engagement often differed by department, implying that there is variation in how departments either explicitly or implicitly encourage, support and facilitate their faculty to engage with decision-makers and/or how faculty in distinct departments perceive engagement. These findings are supported by earlier research on the mediating role of incentives and professional and time costs in knowledge exchange processes [72]. Although departmental affiliation may play an important role in faculty engagement, our findings suggest faculty's research area of expertise was also predictive of how factors were rated. Accordingly, discipline and/or domain-specific norms may also affect faculty perceptions of facilitators and barriers to engagement. For example, faculty with interests in health policy, services and systems research were found to be more likely to rate Personal Networks and Experiential Knowledge as facilitators, which may reflect the unique relational or political norms that exist within the health policy domain.

The variation in responses regarding faculty institutional affiliation suggests that, while an academic institution's brand and reputation can be generally positively viewed, there may be negative experiences or intentions associated with academia that affect the credibility or opportunity for faculty influence. These negative experiences may be attributable to stakeholder experiences regarding 'parachute' consultants, prioritisation of foreign researchers at the expense of local expertise, or past activities in local or international communities that have undermined trust.

\section{Individual characteristics}

Differences in responses and experiences between faculty in professorial and scientist tracks, as well as within each track, suggest the professional norms governing career trajectories may differ. Respondents placed a high value on Personal Networks, which suggests that the importance of relationships with decision-makers has been recognised as critical to influencing decision-making. However, the fact that most senior staff noted the value of their own networks whereas junior staff valued the introductions to relevant colleagues indicates that particular attention needs to be paid to assist faculty in more junior positions to build, nurture and maintain their 
networks. Peer Introductions being one of the top ranked facilitators further supports this assertion. Establishing partnerships between researchers and decision-makers, as well as increasing contact and communication between them have been found to drive engagement [13, 21, 27] and enhance the 'embeddedness' of an organisation [73]. Enhancing relationships with key decision-makers is an area that SPHs - and academic institutions in general should therefore encourage, support and broker.

Faculty that were engaged with decision-makers were more likely to consider a broad range of institutional and individual factors as facilitators than faculty peers who were not engaged. This finding suggests that faculty perceptions of engagement may depend on exposure to successful engagement. Not surprisingly, faculty that had a larger number of relationships were more likely to identify Personal Networks as a facilitator.

Faculty responses regarding Funder Requirements suggest there is variation in whether funders support or encourage engagement with decision-makers and that variation in these policies is apparent in terms of domain. Greater support, guidance or requirements from funders may therefore enhance researcher engagement.

\section{Priorities}

The top priorities identified by respondents emphasised creating additional incentives for engagement through changes to promotion and tenure criteria, supplemental funding for engagement, and reforms to departmental and school culture regarding engagement. These findings were consistent with Academic Incentives and Departmental Reimbursement being identified as barriers by $18.5 \%$ and $15.6 \%$ of respondents, as well as other studies where appropriate incentives as well as funding appeared amongst the most commonly cited barriers [20, 22, 74].

We note that the identified priorities did not always align to the reported facilitators/barriers as expected. For instance, although Time was the most frequently cited barrier, only 26\% prioritised Allocating Time. This may be a reflection of the institutional focus of the priority response options compared to the individual focus of the facilitator and barrier factors. The fact that priorities were consistent across a variety of faculty characteristics (e.g. position, number of years within the institution and departmental affiliation) suggests future interventions should target both specific groups (e.g. faculty in scientist tracks, junior faculty, faculty in certain domains) and the school as a whole. Innovative technology and staffing-related priorities were not well ranked, which suggests such strategies may be underappreciated. These findings were consistent with Brownson et al.'s [60] identification of seven strategies that SPHs may implement to enhance the impact of public health research.

\section{Implications}

The fact that several facilitators as well as barriers to engagement that are relevant to an SPH have been highlighted through this study begs dedicated attention by the institution of the study focus as well as SPHs more widely. Although the reasons why faculty in this study considered certain factors facilitators or barriers as well as their explanations for why the chosen priorities emerged in the way that they did are not known, future research that addresses this question would be valuable.

Interventions affecting faculty engagement with decisionmakers require a systemic approach that considers approaches that span at least four of the five categories of influences articulated in the framework (e.g. individual, institutional, relational, research related). Of note, any interventions aimed at enhancing incentives and/or faculty skill development need to be designed with a view that these would be integral to the broader goal of organisational effectiveness [75], relevance, embeddedness and connectivity. Furthermore, given the variations in results by department, research area of expertise, academic position, career track and rank, any interventions should be tailored to these influences. SPHs would benefit from testing of such interventions empirically to ascertain their utility and effectiveness in enhancing engagement between faculty and decision-makers government or otherwise.

Training and mentorship approaches targeting both faculty and doctoral or masters-level public health students may also help mitigate barriers related to relational skills and individual characteristics [76]. Some lessons could be learned from the University of Cambridge Policy Fellows Programme [42] as well as the University of North Carolina's Thorp Engaged Scholars Program [77].

Like many other SPHs [51, 61, 77], JHSPH has several initiatives underway that reflect its appreciation of EIDM and the role that the institution could play in advancing EIDM. These include advocacy skill-building workshops, seminars to develop and build consensus around policy recommendations, small funding opportunities for the development of dissemination products, placements for decision-makers-in-residence, and creation of a 'Professors of Practice' title for faculty with extensive policy-making experience. However, given that they do not necessarily align with faculty-identified priorities indicates that perhaps well-intentioned interventions could benefit from further faculty input. Stakeholder engagement greatly increases acceptability and uptake of institutional change and interventions [78, 79]. The results of this study may assist with providing the first step in engaging stakeholders (faculty) in contributing to institutional priority-setting. Particular attention to 
strengthen and sustain facilitators as well as alleviate barriers at the institutional as well as individual levels should be a complementary priority henceforth.

Our study suggests that, if indeed SPHs and academic settings intend to further affect change in policy, practice or public goals through the research and expertise embedded within their institutions, they should consider (1) periodically measuring engagement with decision-makers within their institutions in order to understand what the facilitators and barriers are and how they evolve; (2) enhancing interventions to build individual capacity in KT and research communication, taking faculty characteristics into account; (3) institutionalising a culture of EIDM that prioritises academic incentives and related practices for engagement both school-wide and within specific departments, research domains and career tracks; and (4) creating a strategy to expand and nurture trusted, relevant networks and relationships with decision-makers.

\section{Strengths and limitations}

As is the case with all research, there are strengths and limitations of the study. One of the most notable strengths is the application of existing literature on individual, institutional, and relational facilitators and barriers to decision-maker engagement to a specific academic environment (i.e. a SPH). Understanding whether current examination of facilitators and barriers in $\mathrm{KT}$ in the literature are relevant to the context of a SPH was an important first step. Furthermore, we have been able to delineate a novel five-point categorisation of the facilitators and barriers as they are relevant to knowledge exchange in contrast to knowledge utilisation, providing a different focus within the KT cycle.

Contrary to recommendations for involving stakeholders in priority-setting exercises [78, 79], there are no studies that we are aware of that have used academic faculty to contribute to priority-setting in a $\mathrm{SPH}$. By inviting respondents to contribute to $\mathrm{SPH}$ priority-setting, we believe that the list that emerged is more reflective of what should be considered by leadership at JHSPH, and perhaps at other SPHs as well. In addition, by stratifying facilitators and barriers by academic and administrative position, areas of research expertise, network connectedness and other factors, this study clarifies important differences in terms of individual and contextual factors.

The incentives, time considerations and commitments for full-time faculty are likely different than those for part-time faculty. By limiting the study to full-time faculty only, we may be underestimating the impact of the various factors identified on faculty ability to engage with decision-makers. In addition, part-time faculty may report distinct facilitators and barriers given the many unique responsibilities and time constraints that characterise part-time faculty roles. If future studies include both cadres of faculty, it would be interesting to note differences, if any, of how the various factors affect their engagement with decision-makers.

While there was a deliberate limit in scope - due to feasibility - to faculty relationships with government decision-makers as a proxy for influence, we recognise that other actors influential in health policy (non-governmental organisations, philanthropic organisations, civil society organisations and advocacy coalitions) have not been captured.

As oftentimes is the case with surveys, aspects such as 'engagement' or 'decision-maker' may have been subject to interpretation even though definitions were provided in advance. To minimise misinterpretations we (1) provided a list of FAQs with the invitations to clarify the purpose, inclusion criteria and format of the study and (2) administered the surveys personally rather than electronically in order to respond to questions arising from respondents. Given that this was a researcher-administered survey, it is possible that there was also some level of social desirability bias. For instance, there may have been cases where more distant or past relationships were mentioned in order to provide an impression of a larger network. In addition, faculty perceptions of facilitators or barriers to engagement may differ from actual structural facilitators and barriers within the institution.

Given that $22 \%$ of our respondents indicated holding positions in more than one department (or school) leads us to interpret our results with caution given that faculty working across multiple departments are likely to be influenced diffusely rather than explicitly by the cultures of those departments.

Response rates differed by departmental affiliation and were substantially lower amongst departments focused on basic science and biostatistics. Accordingly, the sample size for such departments are small and the regression results have wide confidence intervals. In addition, given the response rate of $34 \%$, these findings may not be fully representative of the overall faculty population. For example, it is possible that faculty that were highly engaged or not engaged self-selected out of study on account of the perception that their work was outside the scope of the study and/or that their contacts were too sensitive.

As is the case with surveys, this study captures experiences at one point in time. In order to capture more longitudinal change in the institution as well as changes in perceptions if indeed some of these interventions are considered, surveys such as these would need to be repeated periodically. 
Lastly, this study focused on a single SPH in order to capture the full breadth of experiences of academics engaging with the decision-making process within one context and the facilitators and barriers that mediate those experiences. Accordingly, study findings may not be generalisable to SPHs or other graduate institutions with fewer faculty or less research funding. Similarly, generalisability may be affected by the geographic location of Johns Hopkins, which is in close proximity to federal government offices in Washington, DC.

\section{Conclusion}

SPHs are increasingly being recognised as important contributors of human, social and intellectual capital relevant to public policy decision-making. While there may be initiatives underway to enhance appreciation of this role as well as strengthen capacity for engagement, this study demonstrates that individual characteristics, institutional factors, relational dynamics, research foci and funder policies interact in a complex manner with respect to academic researchers' engagement with public health decision-makers. Moreover, these data from one SPH suggest that factors differ in their status as a facilitator or barrier in terms of institutional characteristics in conjunction with, and not separate from, individual experiences. Particular attention to strengthen and sustain facilitators as well as alleviate barriers at the institutional as well as individual levels should be a priority. Assuming that funder policies with respect to dissemination and decision-maker engagement requirements are out of the realm of institutional control, it would benefit SPHs to consider an integrated approach to build on their strengths as well as diminish their challenges in the other four areas. Of note, any interventions aimed at faculty skill development need to be designed with a view that these would be integral to the broader goal of organisational effectiveness.

\section{Abbreviations}

EIDM: Evidence-informed decision-making; JHSPH: Johns Hopkins Bloomberg School of Public Health; KT: Knowledge translation; SPH: School of public health

\section{Acknowledgements}

The authors thank the leadership at the Johns Hopkins Bloomberg School of Public Health for their support as well as all the faculty participants for their time and insights. We are also grateful to the reviewers who dedicated their time and expertise to strengthen this paper.

\section{Funding}

The study was conducted through support provided by The Lerner Center for Health Promotion at the Johns Hopkins Bloomberg School of Public Health without restrictions on the research content or approach. The content is solely the responsibility of the authors and does not necessarily represent the official views of the funder.

\section{Availability of data and materials}

The datasets used and/or analysed during the current study are available from the corresponding author on reasonable request.

\section{Authors' contributions}

$\mathrm{NJ}, \mathrm{SS}, \mathrm{MDR}, \mathrm{DH}$ and SH contributed to the design of the study. NJ, SS, CB and MDR were involved in data collection. NJ, SS, MDR and CB were involved in the data analysis and interpretation. All authors contributed to the development of the manuscript and reviewed and approved the final version.

\section{Ethics approval and consent to participate}

This study was approved by the Institutional Review Board of the Johns Hopkins Bloomberg School of Public Health (\#00006968). Respondents provided verbal consent to participate.

\section{Consent for publication}

Not applicable.

\section{Competing interests}

The authors declare that they have no competing interests.

\section{Publisher's Note}

Springer Nature remains neutral with regard to jurisdictional claims in published maps and institutional affiliations.

Received: 15 January 2018 Accepted: 22 June 2018

Published online: 25 July 2018

\section{References}

1. Department of Health and Human Services. Part 1. Overview Information. https://grants.nih.gov/grants/guide/pa-files/par-16-238.html. Accessed 13 July 2018.

2. Task Force on Health Systems Research. Informed choices for attaining the millennium development goals: towards an international cooperative agenda for health-systems research. Lancet. 2004;364(9438):997-1003.

3. Brownson RC, Colditz G, Proctor EK. Dissemination and Implementation Research in Health: Translating Science to Practice. Oxford: Oxford University Press; 2012.

4. Brownson RC, Allen P, Duggan K, Stamatakis KA, Erwin PC. Fostering moreeffective public health by identifying administrative evidence-based practices: a review of the literature. Am J Prev Med. 2012;43(3):309-19.

5. Gollust SE, Kite HA, Benning SJ, Callanan RA, Weisman SR, Nanney MS. Use of research evidence in state policymaking for childhood obesity prevention in Minnesota. Am J Public Health. 2014;104(10):1894-900.

6. Landry $\mathrm{R}$, Lamari $\mathrm{M}$, Amara $\mathrm{N}$. The extent and determinants of the utilization of university research in government agencies. Public Adm Rev. 2003;63(2): 192-205.

7. Innvær S, Vist G, Trommald M, Oxman A. Health policy-makers' perceptions of their use of evidence: a systematic review. J Health Serv Res Policy. 2002; 7(4):239-44

8. Waqa G, Mavoa H, Snowdon W, Moodie M, Schultz J, McCabe M, Kremer P, Swinburn B. Knowledge brokering between researchers and policymakers in Fiji to develop policies to reduce obesity: a process evaluation. Implement Sci. 2013;8:74.

9. Hartung DM, Guise JM, Fagnan LJ, Davis MM, Stange KC. Role of practicebased research networks in comparative effectiveness research. J Comp Eff Res. 2012;1 (1):45-55.

10. Coburn AF. The role of health services research in developing state health policy. Health Aff (Millwood). 1998;17(1):139-51.

11. Ross S, Lavis J, Rodriguez C, Woodside J, Denis JL. Partnership experiences: involving decision-makers in the research process. J Health Serv Res Policy. 2003:8(Suppl 2):26-34.

12. Otten JJ, Dodson EA, Fleischhacker S, Siddiqi S, Quinn EL. Getting research to the policy table: a qualitative study with public health researchers on engaging with policy makers. Prev Chronic Dis. 2015;12:E56.

13. Oliver K, Innvar S, Lorenc T, Woodman J, Thomas J. A systematic review of barriers to and facilitators of the use of evidence by policymakers. BMC Health Serv Res. 2014;14:2.

14. Ellen ME, Léon G, Bouchard G, Ouimet M, Grimshaw JM, Lavis JN. Barriers, facilitators and views about next steps to implementing supports for evidence-informed decision-making in health systems: a qualitative study. Implement Sci. 2014;9:179.

15. Campbell DM, Redman S, Jorm L, Cooke M, Zwi AB, Rychetnik L. Increasing the use of evidence in health policy: practice and views of 
policy makers and researchers. Aust New Zealand Health Policy. 2009; 6(1):21.

16. Hyder AA, Corluka A, Winch PJ, El-Shinnawy A, Ghassany H, Malekafzali H, Ghaffar A. National policy-makers speak out: are researchers giving them what they need? Health Policy Plan. 2010;26(1):73-82.

17. Kothari A, MacLean L, Edwards N. Increasing capacity for knowledge translation: understanding how some researchers engage policy makers. Evid Policy. 2009;5(1):33.

18. Jessani N, Kennedy C, Bennett SC. The human capital of knowledge brokers: an analysis of attributes, capacities and skills of academic teaching and research faculty at Kenyan schools of public health. Health Res Policy Syst. 2016;14:58.

19. Hung SY, Durcikova A, Lai HM, Lin WM. The influence of intrinsic and extrinsic motivation on individuals' knowledge sharing behavior. Int J Hum Comput Stud. 2011;69(6):415-27.

20. Jacobson N, Butterill D, Goering P. Organizational factors that influence university-based researchers' engagement in knowledge transfer activities. Sci Commun. 2004;25(3):246-59.

21. Choi BC, Pang T, Lin V, Puska P, Sherman G, Goddard M, Ackland MJ, Sainsbury P, Stachenko S, Morrison H, Clottey C. Can scientists and policymakers work together? J Epidemiol Community Health. 2005;59(8): 632-7.

22. Mitton C, Adair CE, McKenzie E, Patten SB, Perry BW. Knowledge transfer and exchange: review and synthesis of the literature. Milbank Q. 2007:85(4):729.

23. Jessani N, Kennedy C, Bennett SC. Enhancing evidence-informed decisionmaking: strategies for engagement between public health faculty and policymakers in Kenya. Evid Policy. 2016;13(2):225-53.

24. Ouimet M, Bédard P, Léon G, Dagenais C. Are indicators of faculty members' credibility associated with how often they present research evidence to public or partly government-owned organisations? A crosssectional survey. Evid Policy. 2014;10(1):5-27.

25. van der Arend J. Bridging the research/policy gap: policy officials' perspectives on the barriers and facilitators to effective links between academic and policy worlds. Policy Stud J. 2014;35(6):611-30.

26. El-Jardali F, Lavis J, Moat K, Pantoja T, Ataya N. Capturing lessons learned from evidence-to-policy initiatives through structured reflection. Health Res Policy Syst. 2014;12:2.

27. Lavis JN, Lomas J, Hamid M, Sewankambo NK. Assessing country-level efforts to link research to action. Bull World Health Organ. 2006;84(8):620.

28. Canadian Health Services Research Foundation. Issues in Linkage and Exchange between Researchers and Decision Makers. Ottawa: Canadian Health Services Research Foundation; 1999.

29. Orton L, Lloyd-Williams F, Taylor-Robinson D, O'Flaherty M, Capewell S. The use of research evidence in public health decision making processes: systematic review. PLoS One. 2011;6(7):e21704.

30. Lavis J, Ross S, McLeod C, Gildiner A. Measuring the impact of health research. J Health Serv Res Policy. 2003;8(3):165-70.

31. Colgrove J, Fried LP, Northridge ME, Rosner D. Schools of public health: essential infrastructure of a responsible society and a 21st-century health system. Public Health Rep. 2010;125(1):8-14.

32. Elliott H, Popay J. How are policy makers using evidence? Models of research utilisation and local NHS policy making. J Epidemiol Community Health. 2000;54(6):461-8.

33. Orem JN, Mafigiri DK, Marchal B, Ssengooba F, Macq J, Criel B. Research, evidence and policymaking: the perspectives of policy actors on improving uptake of evidence in health policy development and implementation in Uganda. BMC Public Health. 2012;12:109.

34. Uzochukwu B, Onwujekwe O, Mbachu C, Okwuosa C, Etiaba E, Nyström ME, Gilson $L$. The challenge of bridging the gap between researchers and policy makers: experiences of a health policy research group in engaging policy makers to support evidence informed policy making in Nigeria. Glob Health. 2016;12(1):67.

35. El-Jardali F, Lavis JN, Ataya N, Jamal D. Use of health systems and policy research evidence in the health policymaking in eastern Mediterranean countries: views and practices of researchers. Implement Sci. 2012;7:2.

36. Padilla-Meléndez A, Garrido-Moreno A. Open innovation in universities: what motivates researchers to engage in knowledge transfer exchanges? Int J Entrepreneurial Behav Res. 2012;18(4):417-39.

37. Haynes AS, Derrick GE, Chapman S, Redman S, Hall WD, Gillespie J, Sturk H. From "our world" to the "real world": exploring the views and behaviour of policy-influential Australian public health researchers. Soc Sci Med. 2011; 72(7):1047-55.

38. Reed RL, Kalucy EC, Jackson-Bowers E, Mclntyre E. What research impacts do Australian primary health care researchers expect and achieve? Health Res Policy Syst. 2011;9:40.

39. Lavis JN, Guindon GE, Cameron D, Boupha B, Dejman M, Osei EJ, Sadana R. Bridging the gaps between research, policy and practice in low-and middleincome countries: a survey of researchers. Can Med Assoc J. 2010;182(9):E350-61.

40. Smith JC, Snider DE, Pickering LK, Advisory Committee on Immunization Practices. Immunization policy development in the United States: the role of the advisory committee on immunization practices. Ann Intern Med. 2009;150(1):45-9.

41. Payan DD, Lewis LB, Cousineau MR, Nichol MB. Advocacy coalitions involved in California's menu labeling policy debate: exploring coalition structure, policy beliefs, resources, and strategies. Soc Sci Med. 2017;177:78-86.

42. Cambridge University. Centre for Science and Policy. Research and Policy Engagement. http://www.csap.cam.ac.uk/Research-Policy-Engagement/. Accessed 13 July 2018

43. McGinty EE, Frattaroli S, Appelbaum PS, Bonnie RJ, Grilley A, Horwitz J, Swanson JW, Webster DW. Using research evidence to reframe the policy debate around mental illness and guns: process and recommendations. Am J Public Health. 2014;104(11):e22-6.

44. Lavis J, Boyko J, Gauvin F. Evaluating deliberative dialogues focused on health public policy. BMC Public Health. 2014;14:1287.

45. Meyer M. The rise of the knowledge broker. Sci Commun. 2010;32(1):118.

46. Jessani N, Boulay M, Bennett S. Do academic knowledge brokers exist? Using social network analysis to explore academic research-to-policy networks from six schools of public health in Kenya. Health Policy Plan. 2016;31(5):600-11.

47. Whitchurch C. Shifting identities and blurring boundaries: the emergence of third space professionals in UK higher education. High Educ Q. 2008:62(4):377-96.

48. Wilsdon J, Allen L, Belfiore E, Campbell P, Curry S, Hill S, Jones R, Hill J, Kain R, Johnson B, Kerridge S, Tinkler J, Thelwall M, Wouters P, Viney I. The Metric Tide: Report of the Independent Review of the Role of Metrics in Research Assessment and Management. London: HEFCE; 2015.

49. Friese B, Bogenschneider K. The voice of experience: how social scientists communicate family research to policymakers. Fam Relat. 2009;58(2):229-43.

50. Ouimet M, Amara N, Landry R, Lavis J. Direct interactions medical school faculty members have with professionals and managers working in public and private sector organizations: a cross-sectional study. Scientometrics. 2007;72:307-23.

51. Longest B Jr, Huber G. Schools of public health and the health of the public: enhancing the capabilities of faculty to be influential in policymaking. AJPH. 2010;100(1):49.

52. Ayah R, Jessani N, Mafuta EM. Institutional capacity for health systems research in east and central African schools of public health: knowledge translation and effective communication. Health Res Policy Syst. 2014;12(1):20.

53. Cairney P, Oliver K. Evidence-based policymaking is not like evidence-based medicine, so how far should you go to bridge the divide between evidence and policy? Health Res Policy Syst. 2017;15(1):35

54. Hunter DJ, Frenk J. The birth of public health education. JAMA. 2015:313(11):1105-6

55. Awofeso N. What's new about the "new public health"? Am J Public Health. 2004;94(5):705-9.

56. Institute of Medicine Committee for the Study of the Future of Public Health. The Future of Public Health. Washington, DC: National Academies Press; 1988.

57. Brownson RC, Kreuter MW, Arrington BA, True WR. From the schools of public health. Public Health Rep. 2006;121(1):97-103.

58. Bialek RG, Sorensen AA. The Public Health Faculty/Agency Forum: Linking Graduate Education and Practice: Final Report. Gainesville: University Press of Florida; 1991.

59. O'Neil EH, Shugars DA, Bader JD. Health Professions Education for the Future: Schools in Service to the Nation. San Francisco: Pew Health Professions Commission; 1993.

60. Brownson RC, Kreuter MW, Arrington BA, True WR. Translating scientific discoveries into public health action: how can schools of public health move us forward? Public Health Rep. 2006;121(1):97-103.

61. Livingood WC, Goldhagen J, Little WL, Gornto J, Hou T. Assessing the status of partnerships between academic institutions and public health agencies. Am J Public Health. 2007;97(4):659-66.

62. Gordon AK, Chung K, Handler A, Turnock BJ, Schieve LA, Ippoliti P. Final report on public health practice linkages between schools of public health and state health agencies. J Public Health Management And Practice. 1999;5(3):25-34 
63. Schieve LA, Handler A, Gordon AK, Ippoliti P, Turnock BJ. Public health practice linkages between schools of public health and state health agencies: results from a three-year survey. J Public Health Manag Pract. 1997;3(3):29-36.

64. Johns Hopkins School of Public Health. School at a Glance. https://www. jhsph.edu/about/school-at-a-glance/index.html. Accessed 13 July 2018.

65. Qualtrics. www.qualtrics.com. Accessed 13 July 2018.

66. Jessani NS, Babcock C, Siddiqi S, Davey-Rothwell M, Ho S, Holtgrave DR. Relationships between public health faculty and decision-makers at four governmental levels: a social network analysis. Evid Policy. 2018. https://doi. org/10.1332/174426418X15230282334424.

67. Milton NR. Knowledge Acquisition in Practice: A Step-by-Step Guide. London: Springer Science \& Business Media; 2007.

68. Tabak RG, Khoong EC, Chambers DA, Brownson RC. Bridging research and practice: models for dissemination and implementation research. Am J Prev Med. 2012:43(3):337-50.

69. Bornbaum CC, Kornas K, Peirson L, Rosella LC. Exploring the function and effectiveness of knowledge brokers as facilitators of knowledge translation in health-related settings: a systematic review and thematic analysis. Implement Sci. 2015;10(1):162.

70. StataCorp LP. Stata Statistical Software: Release 14. College Station: StataCorp LP; 2015.

71. Johns Hopkins University. JHU Report on Faculty Composition. Baltimore: Johns Hopkins University; 2016.

72. Contandriopoulos D, Lemire M, Denis JL, Tremblay É. Knowledge exchange processes in organizations and policy arenas: a narrative systematic review of the literature. Milbank Q. 2010;88(4):444-83.

73. Koon AD, Rao KD, Tran NT, Ghaffar A. Embedding health policy and systems research into decision-making processes in low-and middle-income countries. Health Res Policy Syst. 2013;11:30.

74. Fraser I. Organizational research with impact: working backwards. Worldviews Evid-Based Nurs. 2004;1(Suppl_1):S52-9.

75. Sibbald SL, PA SI, Upshur R, Martin DK. Priority setting: what constitutes success? A conceptual framework for successful priority setting. BMC Health Serv Res. 2009;9:43.

76. Menon D, Stafinski T, Martin D. Priority-setting for healthcare: who, how, and is it fair? Health Policy. 2007;84(2-3):220-33.

77. Carolina Center for Public Service. UNC-Chapel Hill Faculty Recognized for Engaged Scholarship Connecting with Community. http://ccps.unc.edu/uncchapel-hill-faculty-recognized-engaged-scholarship-connecting-community/. Accessed 13 July 2018

78. Centre for Higher Education Transformation (CHET). Capacity Building Initiatives in Higher Education. Stellenbosch: CHET; 2002.

79. Stamatakis KA, Norton WE, Stirman SW, Melvin C, Brownson RC. Developing the next generation of dissemination and implementation researchers: insights from initial trainees. Implement Sci. 2013;8:29.

Ready to submit your research? Choose BMC and benefit from:

- fast, convenient online submission

- thorough peer review by experienced researchers in your field

- rapid publication on acceptance

- support for research data, including large and complex data types

- gold Open Access which fosters wider collaboration and increased citations

- maximum visibility for your research: over $100 \mathrm{M}$ website views per year

At $\mathrm{BMC}$, research is always in progress.

Learn more biomedcentral.com/submissions 